Article

\title{
On the Sustainable Choice of Alloying Elements for Strength of Aluminum-Based Alloys
}

\author{
Anders E.W. Jarfors ${ }^{1,2}, * \mathbb{D}$, Andong Du ${ }^{2}$, Gegan $\mathrm{Yu}^{2}$, Jinchuan Zheng ${ }^{2}$ and Kaikun Wang ${ }^{3}$ \\ 1 Jönköping University, School of Engineering, Department of Materials and Manufacturing, Box1026, \\ 55111 Jönköping, Sweden \\ 2 China Academy of Machinery Sciences and Technology (Jiangle) Institute of Semi-solid Metal Technology, \\ No 22 Huancheng East Road, Jiangle County, Sanming City 353300, China; B20170186@xs.ustb.edu.cn (A.D.); \\ yugg@cam.com.cn (G.Y.); zhengjc@cam.com.cn (J.Z.) \\ 3 University of Science and Technology Beijing, School of Materials Science and Engineering, Department of \\ Materials Processing and Control Engineering, Xueyuan Road No.30, Haidian District, Beijing 100083, China; \\ kkwang@mater.ustb.edu.cn \\ * Correspondence: anders.jarfors@ju.se
}

Received: 11 January 2020; Accepted: 28 January 2020; Published: 2 February 2020

\begin{abstract}
Aluminum alloys are today entirely recyclable and are seen as a sustainable material. However, there are limitations in the use of aluminum from material strength and cost perspective. Nickel, copper and rare earth metals are alloying elements that may provide strength at room and elevated temperatures. These are, however, often seen as harmful from a sustainability viewpoint. Additionally, these alloying elements are commonly costly. The current paper makes an analysis of the sustainability-strength dimension of alloying, together with a cost perspective, to guide alloy producers and alloy users in making an educated choice of direction for future materials and material development.
\end{abstract}

Keywords: aluminum; alloys; alloying element; cost; strength; sustainability; embodied energy; $\mathrm{CO}_{2}$-footprint; water usage

\section{Introduction}

Lightweight components and weight reduction have significant impacts on energy used and greenhouse gas emissions from transport in and between cities. City transport emissions are partly related to wealth, but the underlying factors are automobile dependence and public transport systems [1]. The energy usage, $\mathrm{CO}_{2}$-footprint as well as gaseous and particle emissions in cities poses a problem and dramatic changes are currently taking place in the transport industry with stricter regulations on emission from legislation and requirements [2]. Legislations and societal trends have put considerable pressure on the transport industry to change towards fully or partially electrified drive trains. The electrification of the drive trains will reduce particle emissions, but the $\mathrm{CO}_{2}$-footprint is high dependent on the nature of the electricity generation and material production. Serrenho et al. [3] analyzed the effect of vehicle weight reduction and concluded that during the transition to a fossil-free electricity generation, weight reduction of vehicles could produce greater cumulative emissions savings by 2050 than those obtained by the electrification alone. It can safely be concluded that to maximize energy and fuel utilization, lightweight designs and material selection are of great importance. In this aspect aluminum and magnesium alloys are the most effective engineering solutions due to their low densities. Cost and recycling methods available makes aluminum superior for the circular economy [4].

In the alloy development of aluminum, there are a number of alloying principles to achieve strength for both wrought and cast alloys [5-7]. The typical mechanisms used are (1) grain refinement, 
(2) precipitation hardening, (3) solution hardening, and for multiphase microstructures there are (4) load bearing effects, (5) thermal expansion mismatch effects and (6) dispersion hardening effects. As the material starts to deform, there will also be effects from deformation hardening in individually deforming phases and effects from modulus mismatch in multiphase systems [6,7]. All this results in a complex solution for alloying systems including effects from processing in the as processed state and effects from heat treatments. Most of the alloying work is focused on optimizing these effects while most of the sustainable analysis concentrates on the use of the materials in components. No significant effort is made on sustainable alloying, meaning how to select or prioritize for a sustainable selection for a specific purpose such as yield strength or tensile strength.

In alloying, there is, from a business perspective, always the issue of cost, and in its purest sense, this is the cost per $\mathrm{kg}$ for alloying elements. From a sustainability standpoint, this may also be part of the sustainability measure. Sustainable measures including cost or geopolitical matters also have several different measures. Being able to operate in a long-term perspective, price volatility of the alloying elements is important [8]. On the country level, sourcing and impacts on the environment and the geographical aspects are measured using the Herfindahl-Hirschmann index (HHI) [8]. All these latter have also been generated to cover larger geopolitical aspects of sustainability. For the alloy developer, these matters may be important, but the immediate and overhanging issues are more related to resource efficiency, energy usage and carbon footprint, related to the global warming issues drawn out in the Charney report [9]. As a consequence of this light-weighting, all transports are critical to addressing the global warming issues [3].

The current study takes as a starting point that aluminum is suitable for making designs lighter. In this, strength is essential, and in vehicles, crash safety is also of importance, and as such a suitable measure used to contextualize alloy development is the tensile strength contribution of the alloying elements. The work is delimited to what the alloy manufacturer can control and that is the embodied energy, $\mathrm{CO}_{2}$-footprint and water usage. The effect of alloying element cost is also addressed in the paper. The result will be a ranking of the possible elements to achieve best possible strength in the as-fabricated state (-F or -O states) with the long-term aim to avoid secondary processing as these add cost, emissions and resources.

\section{Methodology}

In the current study, data from literature and databases was taken to allow for a generalized analysis of the effectiveness of the alloying elements and the associated environmental loading. A series of indexes were generated as a measure of the environmental impact of these elements to guide the development of alloys for a sustainable future, divided into three main directions of discussion.

\subsection{Alloying Element Strength Contribution}

As the strength contribution is very complex and for the development of a comprehensive measure, two different approaches to the generation of the index were taken with inspiration taken from the typical contributions from solution hardening and precipitation hardening and composite structures [6,7].

The linear approach related more to particle precipitation and second phase generation:

$$
\sigma=\sum_{i} a_{i} x_{i}
$$

The square root approach related more to solution hardening effects of the alloying:

$$
\sigma=\sum_{i} a_{i} \sqrt{x_{i}}
$$


where $a_{i}$ is the strength coefficient, and $x_{i}$ is the weight per cent of the alloying addition for element $i$. The strength coefficient is essential for the remainder of the discussion as a high strength coefficient opens the possibility for a maximum outcome with a minimum of addition. It should here be noted that the aim is not to describe solution precipitation nor to describe precipitation hardening but to create an index allowing to one to contextualize the environmental impact of the strength contribution of the content of an alloying element. The choice of property is also important and for the current case this was the ultimate tensile strength or UTS, which was chosen as it contains failure behavior implicitly through deformation hardening during the plastic elongation to failure. Data was also chosen in the as-fabricated state (-F or -O states), as heat treatment and secondary processing should be avoided in the ideal case to minimize cost and environmental impact. The data used is collated in the Appendix A Table A1.

\subsection{Environmental Alloying Efficiency Index for Alloying Elements}

To construct a measure to guide the alloy developers in the selection of alloying element candidates, the contribution to strength must be leveraged by the environmental load. In doing this, the strength coefficient for each element $i$, should be divided with the environmental load for each one of the loads, (1) embodied energy, $b_{i},\left(\mathrm{MJ} / \mathrm{kg}_{i}\right)$, (2) $\mathrm{CO}_{2}$-footprint, $c_{i},\left(\mathrm{~kg}_{\mathrm{CO} 2} / \mathrm{kg}_{i}\right)$ and water usage, $d_{i},\left(\mathrm{l} / \mathrm{kg}_{i}\right)$. The three measures $\mathrm{E}_{\mathrm{i}}\left(\mathrm{MPa} . \mathrm{kg}_{i} /(\mathrm{MJ} \%\right.$ element $\left.i)\right)$, characterizing energy efficiency for element $i, \mathrm{E} 2_{\mathrm{i}}$ $\left(M P a . \mathrm{kg}_{\mathrm{i}} /\left(\mathrm{kg}_{\mathrm{CO} 2} \%\right.\right.$ element $\left.\left.\mathrm{i}\right)\right)$, characterizing carbonfootprint for element $\mathrm{I}$, and $\mathrm{E} 3_{\mathrm{i}}\left(\mathrm{MPa} . \mathrm{kg}_{\mathrm{i}} /(1 \%\right.$ element $i)$ ), characterizing water usage for element $i$, can thus be expressed as:

$$
\begin{aligned}
\mathrm{E} 1_{i} & =\frac{a_{i}}{b_{i}} \\
\mathrm{E} 2_{i} & =\frac{a_{i}}{c_{i}} \\
\mathrm{E} 3_{i} & =\frac{a_{i}}{d_{i}}
\end{aligned}
$$

\subsection{Environmental Alloying Efficiency Index with Alloying Element Cost Weighting}

The creation of a new set of environmental impact indices contextualized with the element's ability to generate strength with cost weighting for each alloying element, $M i,(R M B / \mathrm{kg})$ can be constructed as:

$$
\begin{aligned}
\mathrm{EM}_{1} & =\frac{a_{i}}{b_{i} M_{i}} \\
\mathrm{EM}_{2} & =\frac{a_{i}}{c_{i} M_{i}} \\
\mathrm{EM}_{3} & =\frac{a_{i}}{d_{i} M_{i}}
\end{aligned}
$$

Here $\mathrm{EM} 1_{\mathrm{i}}\left(\mathrm{MPa} \cdot \mathrm{kg}_{i}{ }^{2} /(R M B \mathrm{MJ} \%\right.$ element $\left.i)\right)$ signifies, as E1i, the ability to generate strength with the smallest impact through the embodied energy but now also including alloying element cost. $\mathrm{EM} 2_{\mathrm{ii}}\left(\mathrm{MPa} . \mathrm{kg}_{\mathrm{i}}{ }^{2} /\left(\mathrm{RMB} \mathrm{kg}_{\mathrm{CO} 2} \%\right.\right.$ element $\left.\left.\mathrm{i}\right)\right)$ signifies, as $\mathrm{E} 2_{\mathrm{ii}}$, the ability to generate strength with the smallest impact through the $\mathrm{CO}_{2}$-footprint but also taking cost-effectiveness into account Similarly, $\mathrm{EM}_{\mathrm{i}}\left(\mathrm{MPa} . \mathrm{kg}_{\mathrm{i}}{ }^{2} /(\mathrm{RMB} \mathrm{l} \%\right.$ element $\left.\mathrm{i})\right)$ signifies, as E3i, the effect of the impact on water usage when cost-effectiveness is considered.

\section{Results and Discussion}

The results and discussion section is divided into three main subsections. The first subsection is an analysis of the strength contribution, and the second part is the environmental impact. The third and last take the environmental impact and add cost to the analysis. 


\subsection{Alloying Element Strength Contribution}

The relationship between the alloying element and the resulting tensile strength were obtained by using data from the ASM Handbook on typical compositions and tensile strengths at room temperature, Table A1, in the Appendix A. This was made for material in the as-cast state for cast alloys and in the as-fabricated state for wrought alloys. The data for alloys in the heat-treated state were omitted, as the primary target for the current report was non-heat-treated materials due to the fact that in the effort to reduce environmental impact, adding additional processing steps, such as a heat treatment, would increase the embodied energy and thus also the $\mathrm{CO}_{2}$-footprint.

The coefficients were obtained using the generalized reduced gradient solver in Excel with a multi-start option of a population of 10,000 to compensate for the potential shortcomings of the solver. The optimization target was to minimize the sum of squares for the whole population. The linear solution showed a value of $92 \%$ of that of the root equation of why the linear solution was deemed superior. The results for the linear approach are shown in Figure 1a and for the root approach are shown in Figure 1b. The actual prediction quality is reasonable to use the coefficient $a_{i}$ in the following analysis for quantitative contextualization.

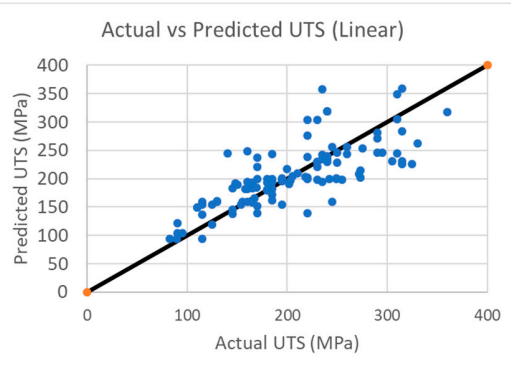

(a)

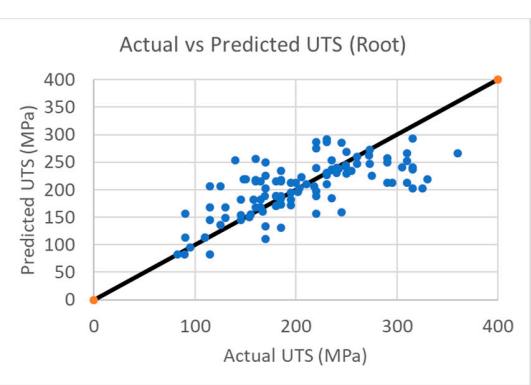

(b)

Figure 1. Actual values versus predicted values for (a) the linear approach and (b) the root approach.

The actual values for the strength coefficients using the linear model are collated in Table 1. It should here be noted that these values were for room temperature and tensile strength. A negative value indicated that when using that alloying element, a reduction of the room temperature strength was the result. It should here be noted that $\mathrm{Er}, \mathrm{Y}$ and Fe were particularly harmful to the room temperature properties. Ni also had a negative influence, as well as Be. All elements with a negative strength coefficient counteract the effort in increasing the strength of the material and as such, should be avoided. The elements with a negative influence were not part of the analysis as the general intent was to avoid negative influence. There were naturally novel alloy design concepts for which the current description failed to describe with higher Fe contents, such as the Castaduct ${ }^{\mathrm{TM}}$ alloy [10]. This was a limitation of the current study and it was only valid for modification and development of existing alloys.

Table 1. The obtained values of the strength coefficient, $a_{i}$, for the linear approach.

\begin{tabular}{ccccccccc}
\hline Element & $\mathbf{A l}$ & $\mathbf{S i}$ & $\mathbf{F e}$ & $\mathbf{C u}$ & $\mathbf{M n}$ & $\mathbf{M g}$ & $\mathbf{C r}$ & $\mathbf{N i}$ \\
\hline$a_{i}($ MPa./\% element $i)$ & 93.54 & 12.72 & -33.98 & 7.01 & 45.41 & 31.97 & 98.24 & -12.27 \\
\hline Element & $\mathbf{Z n}$ & $\mathbf{T i}$ & $\mathbf{B e}$ & $\mathbf{S n}$ & $\mathbf{C e}$ & $\mathbf{L a}$ & $\mathbf{Y}$ & $\mathbf{E r}$ \\
\hline$a_{i}($ MPa./\% element $i)$ & 12.30 & 0.01 & -0.91 & 6.30 & 64.98 & 31.61 & -47.75 & -54.95 \\
\hline
\end{tabular}

\subsection{Environmental Load From Alloying Elements}

The data for the environmental loads were chosen such that the geopolitical aspects were not considered in this first step, but rather the matter that would have a substantial effect on energy usage and carbon footprint as these are intimately connected through the energy source used [3]. In this part, 
the assumption of the use of the best available technology (BAT) was made. Water is also one of the more critical resources and therefore, the use of water was also brought into the analysis. All data were taken from the Cambridge Engineering Selector (CES) software [8].

The chosen measures for the environmental load were (1) embodied energy, $\mathrm{b}_{\mathrm{i}},\left(\mathrm{MJ} / \mathrm{kg}_{\mathrm{i}}\right)$, (2) $\mathrm{CO}_{2}$-footprint, $\mathrm{c}_{\mathrm{i}},\left(\mathrm{kg}_{\mathrm{CO} 2} / \mathrm{kg}_{i}\right)$ and water usage, $\mathrm{d}_{\mathrm{i}},\left(\mathrm{l} / \mathrm{kg}_{i}\right)$. The data available were collated in Table 2, also indicating the data chosen for the current analysis.

Table 2. Environmental impact in the form of the three environmental loads from the different alloying element and the chosen value for the current study. The chosen data according to the assumption of best available technology (BAT) are the values in parentheses [8].

\begin{tabular}{cccc}
\hline Element & $\begin{array}{c}\mathbf{b}_{\mathbf{i}} \\
\text { Embodied Energy (MJ/kg) } \\
\text { Primary Production }\end{array}$ & $\begin{array}{c}\mathbf{c}_{\mathbf{i}} \\
\left.\mathbf{C O}_{\mathbf{2}} \text { Footprint } \mathbf{( k g / k g}\right) . \\
\text { Primary Production }\end{array}$ & $\begin{array}{c}\mathbf{d}_{\mathbf{i}} \\
\text { Water Usage (L/kg). } \\
\text { Pure Element }\end{array}$ \\
\hline $\mathrm{Si}$ & $116-128(116)$ & $4.78-5.27(4.78)$ & $23.2-25.7(23.2)$ \\
$\mathrm{Fe}$ & $23.2-25.6(23.2)$ & $2.18-2.4(2.18)$ & $44.9-49.6(44.9)$ \\
$\mathrm{Cu}$ & $56.1-61.9(51.6)$ & $3.44-3.79(3.44)$ & $297-328(297)$ \\
$\mathrm{Mn}$ & $55.8-61.5(55.8)$ & $3.8-4.19(3.8)$ & $231-256(231)$ \\
$\mathrm{Mg}$ & $310-342(310)$ & $44.2-48.7(44.2)$ & $930-1030(930)$ \\
$\mathrm{Cr}$ & $550-606(550)$ & $20-22.1(20)$ & $451-498(451)$ \\
$\mathrm{Ni}$ & $159-175(159)$ & $11.2-12.3(11.2)$ & $79-377(79)$ \\
$\mathrm{Zn}$ & $44-48.5(44)$ & $3.46-3.82(3.46)$ & $327-361(361)$ \\
$\mathrm{Ti}$ & $559-616(559)$ & $31.6-34.9(34.9)$ & $(110)$ \\
$\mathrm{Be}$ & $6080-67,000(6080)$ & $821-905(821)$ & $340-379(340)$ \\
$\mathrm{Zr}$ & $1530-1690(1530)$ & $98.1-108(98.1)$ & $262-289(262)$ \\
$\mathrm{Ce}$ & $493-544(493)$ & $32.4-35.8(32.4)$ & $52.4-57.9(524)$ \\
$\mathrm{La}$ & $258-284(258)$ & $16.7-18.4(16.7)$ & $52.7-58.2(52.7)$ \\
$\mathrm{Y}$ & $1400-1540(1400)$ & $84.8-93.5(84.8)$ & $52.4-57.9(52.4)$ \\
$\mathrm{Er}$ & $2810-3100(2810)$ & $188-207(188)$ & $52.7-58.2(52.7)$ \\
\hline
\end{tabular}

\subsection{Environmental Alloying Efficiency Index for Alloying Elements}

The environmental efficiency indexes for alloying elements are shown in Figure 2 for the index $\mathrm{E} 1_{\mathrm{i}}$, Figure 3 for index $\mathrm{E} 2_{\mathrm{i}}$ and Figure 4 for index $\mathrm{E} 3_{\mathrm{i}}$.

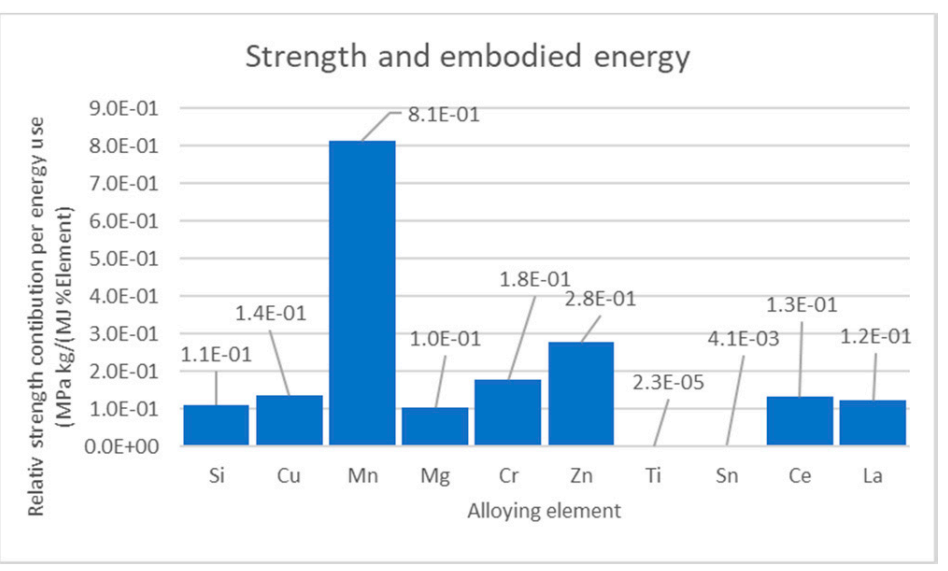

Figure 2. Strengths contribution by alloying per embodied energy, $\mathrm{E} 1_{\mathrm{i}}$. 


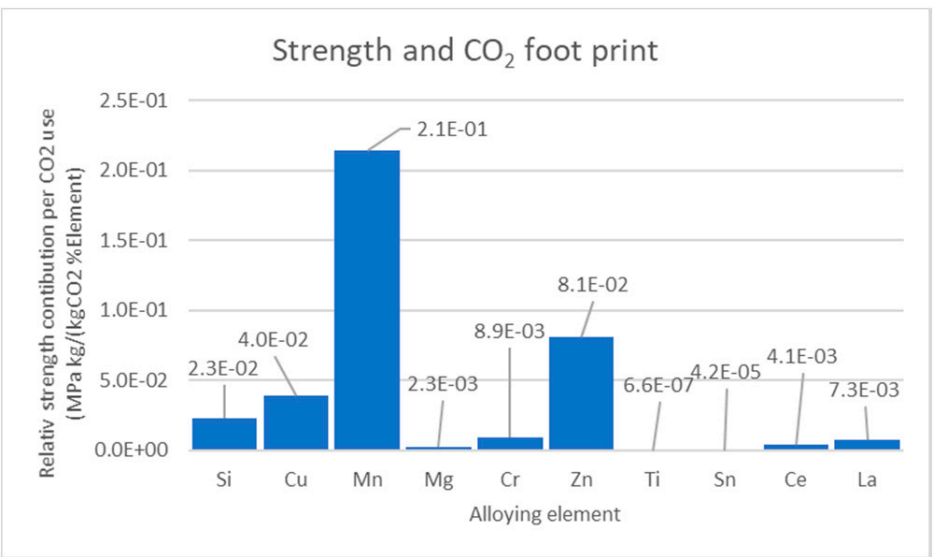

Figure 3. Strengths contribution by alloying per embodied energy, E2 ${ }_{\mathrm{i}}$.

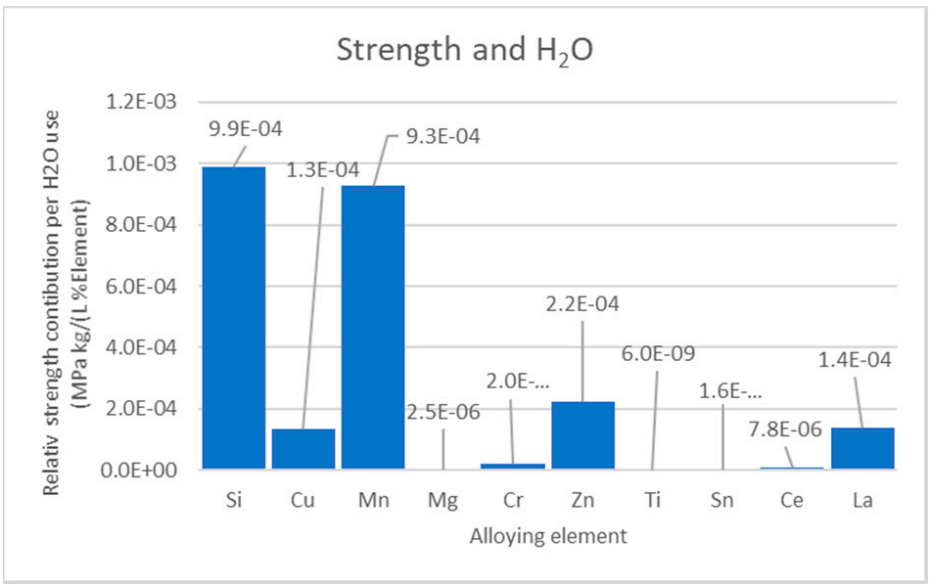

Figure 4. Strength contribution by alloying per water usage, $\mathrm{E} 3_{\mathrm{i}}$.

As seen in Figure 2 the results for $\mathrm{E} 1_{\mathrm{i}}$ and the most efficient element to use for high strength with a minimum of environmental impact through embodied energy was Mn with $\mathrm{Zn}$ as second followed by $\mathrm{Cr}$. It is worthwhile noting that the common alloying elements $\mathrm{Si}, \mathrm{Cu}$ and $\mathrm{Mg}$ were on par with $\mathrm{Ce}$ and La. Important to note here is that this analysis was valid for primary alloys.

$\mathrm{CO}_{2}$-footprint is more important today following the discovery of the greenhouse effect reported in the so-called Charney report [9]. The findings for the $\mathrm{CO}_{2}$-footprint followed the same pattern as that of the embodied energy. The most effective alloying element was $\mathrm{Mn}$, followed by $\mathrm{Zn}$ and then $\mathrm{Cu}$ and $\mathrm{Si}$. The elements $\mathrm{Mg}, \mathrm{Cr}, \mathrm{Ce}$ and $\mathrm{La}$ were roughly on par. For the $\mathrm{CO}_{2}$-footprint, $\mathrm{Cu}$ and $\mathrm{Si}$ were more beneficial than $\mathrm{Mg}, \mathrm{Cr}$, Ce and $\mathrm{La}$, a difference that was less pronounced for the embodied energy.

The results for the water usage was different compared to that of both the embodied energy and $\mathrm{CO}_{2}$-footprint. $\mathrm{Mn}$ and $\mathrm{Zn}$ were still among the best elements, but $\mathrm{Si}$ was the most effective element with $\mathrm{Zn}, \mathrm{Cu}$ and La being nearly on par with each other in producing strength with little water.

\subsection{Environmental Alloying Efficiency Index with Alloying Element Cost Weighting}

Cost of alloys and processes is often a determining factor in enabling the use of a material [11]. In the current analysis, the cost of alloys was based on the Chinese metal market with reference taken in September 2019 (Figure 5). The cost of alloying element $\left(\mathrm{M}_{\mathrm{i}},(R M B / \mathrm{kg})\right.$ ) varied strongly with Fe being the lowest and Be the costliest. It should also be noted that $\mathrm{Ce}$ and La were in the same price range as other common alloying materials such as $\mathrm{Mg}, \mathrm{Cu}$ and $\mathrm{Cr}$, while $\mathrm{Y}$ and Er were significantly more costly [12]. 


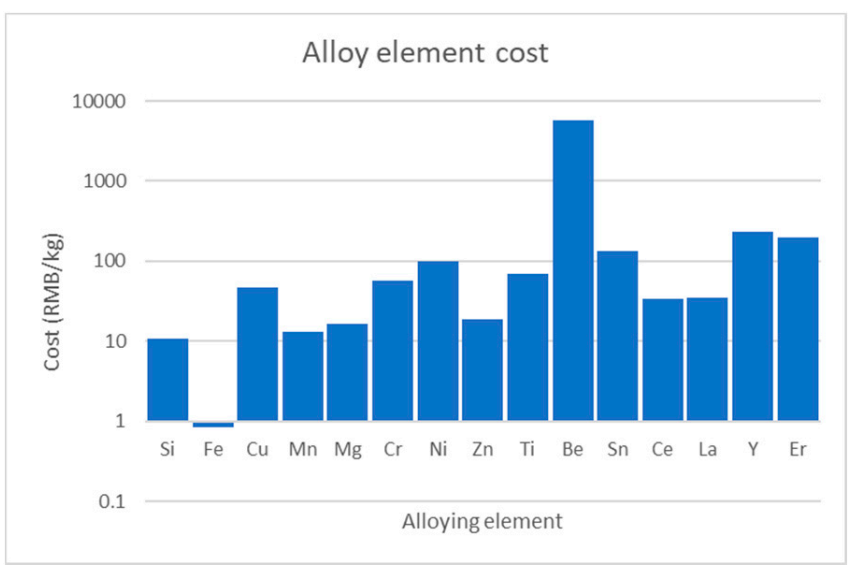

Figure 5. Alloying element cost basis for the estimation of influence of cost. Source: Chinese metal market September 2019.

The result for $\mathrm{EM}_{\mathrm{i}}$, as seen in Figure 6, was only slightly altered from the E1i results. Mn was the most cost-effective way to improve strength with the least amount of embodied energy and unit cost. Second was $\mathrm{Zn}$ and then $\mathrm{Si}$. Mg was slightly above $\mathrm{Cr}, \mathrm{Cu}, \mathrm{Ce}$ and $\mathrm{La}$, which were on par. Repeating the process and studying the outcome for $\mathrm{EM} 2_{\mathrm{i}}$ signified, as $\mathrm{E} 2_{\mathrm{i}}$, the ability to generate strength with the smallest impact through the $\mathrm{CO}_{2}$-footprint but also taking cost-effectiveness into account; the result was similar to the $\mathrm{E} 1_{\mathrm{i}}$ results, Figure 7. The variation was, however, higher. Again, Mn was the most cost-effective way to improve strength with the smallest $\mathrm{CO}_{2}$-footprint and unit cost. Second was $\mathrm{Zn}$, followed by $\mathrm{Si}$ and $\mathrm{Cu}$ and then $\mathrm{Mg}, \mathrm{Cr}, \mathrm{Ce}$ and $\mathrm{La}$, which were on par.

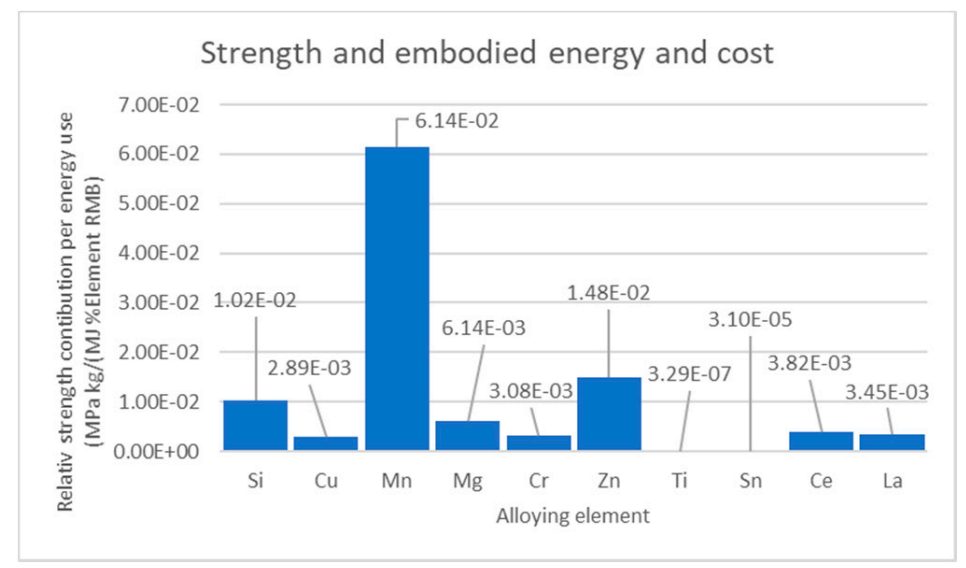

Figure 6. Embodied energy and strength index with cost weighting, EM1 $1_{i}$.

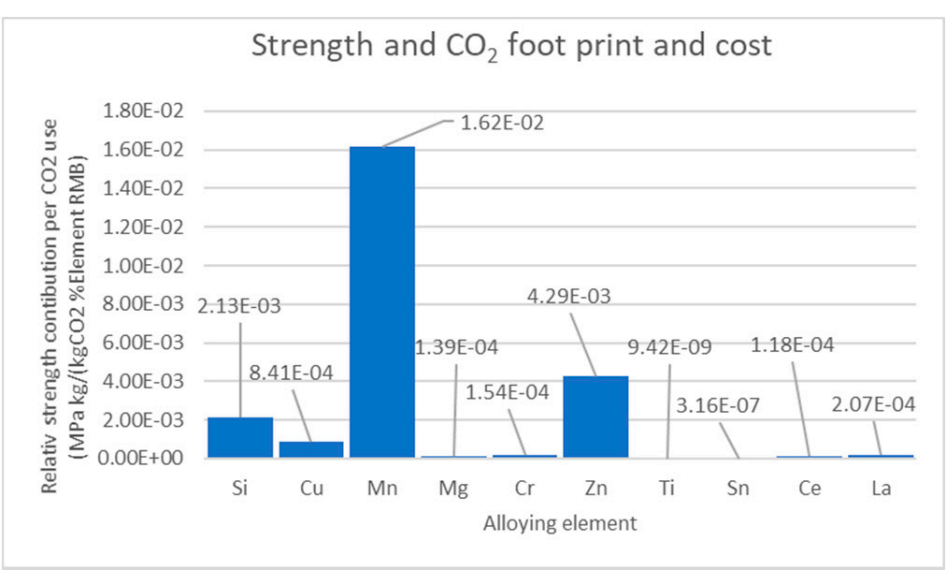

Figure 7. $\mathrm{CO}_{2}$-footprint and strength index with cost weighting, $\mathrm{EM} 2_{\mathrm{i}}$. 
The analysis made above on $\mathrm{E}_{\mathrm{i}}$ compared to that of $\mathrm{E}_{\mathrm{i}}$ and $\mathrm{E} 2_{\mathrm{i}}$ showed that the effect on the impact on water usage showed a different pattern, which also was the case when studying the outcome for $\mathrm{EM}_{\mathrm{i}}$ when cost-effectiveness was considered, Figure 8. The main difference was that Mn was the best solution when cost-effectiveness was included, but for the environmental impact alone, Si was the preferred element but only by a slim margin compared to $\mathrm{Mn}$. For the $\mathrm{EM}_{\mathrm{i}}$ index, $\mathrm{Mn}$ was without competition the superior solution followed by $\mathrm{Si}$ and then $\mathrm{Cu}$ and $\mathrm{La}$. One order of magnitude lower then followed $\mathrm{Mg}, \mathrm{Cr}$ and $\mathrm{Ce}$.

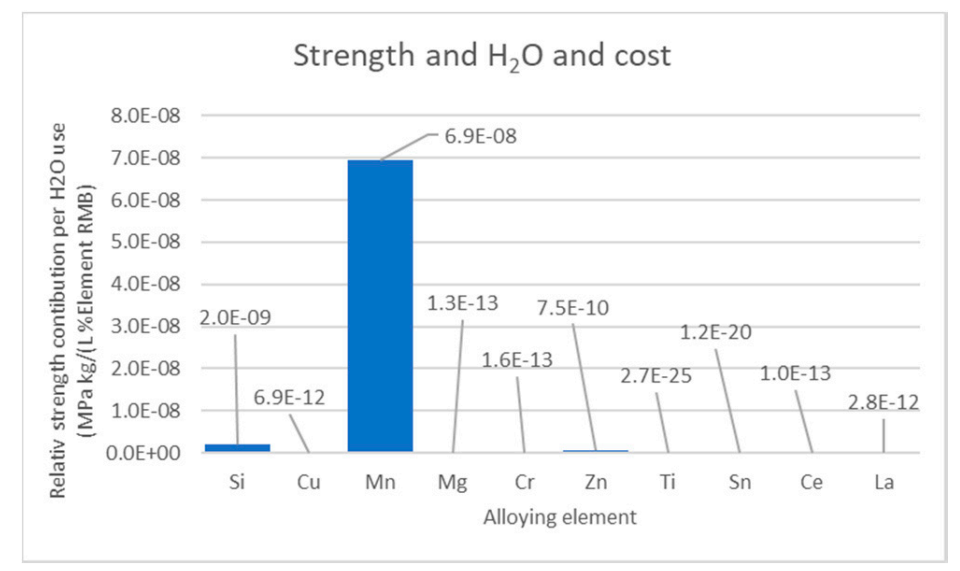

Figure 8. Water usage and strength index with cost weighting, $\mathrm{EM} 3_{\mathrm{i}}$.

\section{Conclusions}

From an effectiveness standpoint, $\mathrm{Mn}$ is the overall preferred element of choice followed by $\mathrm{Zn}$ and then Si with and without cost penalty, as seen in Table 3. In the table, the ranking from the derived indices are shown and the sum of the ranking with and without cost is shown. In the analysis of the impact, the overall ranking is shown within parentheses.

Table 3. The ranking using the 6 different indexes derived and the total impact ranking.

\begin{tabular}{|c|c|c|c|c|c|c|c|c|}
\hline Element & $\begin{array}{c}\text { Rank by } \\
\quad \mathbf{E 1}_{\mathbf{i}}\end{array}$ & $\begin{array}{c}\text { Rank by } \\
\text { EM1 }_{i}\end{array}$ & $\begin{array}{c}\text { Rank by } \\
\text { E2 }\end{array}$ & $\begin{array}{c}\text { Rank by } \\
\text { EM2 } 2_{i}\end{array}$ & $\begin{array}{c}\text { Rank by } \\
\text { E3 }_{i}\end{array}$ & $\begin{array}{c}\text { Rank by } \\
\text { EM3 }_{i}\end{array}$ & $\begin{array}{l}\text { Impact } \\
E 1_{i}+E 2_{i} \\
\quad+E 3_{i}\end{array}$ & $\begin{array}{c}\text { Impact } \\
\text { EM1 }_{\mathrm{i}}+\mathrm{EM} 2_{\mathrm{i}} \\
+\mathrm{EM} 3_{\mathrm{i}}\end{array}$ \\
\hline $\mathrm{Si}$ & 7 & 3 & 4 & 3 & 1 & 2 & $12(3)$ & $8(3)$ \\
\hline $\mathrm{Fe}$ & Negative & Negative & Negative & Negative & Negative & Negative & - & - \\
\hline $\mathrm{Cu}$ & 4 & 8 & 3 & 4 & 5 & 4 & $12(3)$ & $16(4)$ \\
\hline $\mathrm{Mn}$ & 1 & 1 & 1 & 1 & 2 & 1 & $4(1)$ & $3(1)$ \\
\hline $\mathrm{Mg}$ & 8 & 4 & 8 & 7 & 8 & 7 & $24(8)$ & $19(6)$ \\
\hline $\mathrm{Cr}$ & 3 & 7 & 5 & 6 & 6 & 6 & $14(5)$ & $19(6)$ \\
\hline $\mathrm{Ni}$ & Negative & Negative & Negative & Negative & Negative & Negative & - & - \\
\hline $\mathrm{Zn}$ & 2 & 2 & 2 & 2 & 3 & 3 & $7(2)$ & $7(2)$ \\
\hline $\mathrm{Ti}$ & 10 & 10 & 10 & 10 & 10 & 10 & $30(10)$ & $30(10)$ \\
\hline $\mathrm{Be}$ & Negative & Negative & Negative & Negative & Negative & Negative & - & - \\
\hline Sn & 9 & 9 & 9 & 9 & 9 & 9 & $27(9)$ & $27(9)$ \\
\hline $\mathrm{Ce}$ & 5 & 5 & 7 & 8 & 7 & 8 & $19(7)$ & $21(8)$ \\
\hline $\mathrm{La}$ & 6 & 6 & 6 & 5 & 4 & 5 & $16(6)$ & $16(4)$ \\
\hline $\mathrm{Y}$ & Negative & Negative & Negative & Negative & Negative & Negative & - & - \\
\hline Er & Negative & Negative & Negative & Negative & Negative & Negative & - & - \\
\hline
\end{tabular}

$\mathrm{Mn}$ is the most effective element and has a slight relative advantage based on cost. $\mathrm{Zn}$ is not affected by cost while $\mathrm{Si}$, ranked third, has a slight benefit from cost. Copper, which based on environmental impact is ranked third, is punished by cost and drops one position based on cost. It should here be noted that $\mathrm{Cu}$ has an ecotoxic nature, which is not reflected in the current analysis. $\mathrm{Cr}$ ranked fifth but also has a negative effect based on cost and drops a position when the cost is included. La is ranked sixth and Ce is ranked seventh based on environmental impact. La and Ce are unexpectedly ranked 
above $\mathrm{Mg}$, which is ranked eighth. Taking cost into account, $\mathrm{Mg}$ and Ce switch place, giving $\mathrm{Mg}$ a cost advantage. La has a substantial cost advantage, making it leapfrog to fourth position when taking cost into account. The research on rare earth materials is strong in China [13]. The current analysis shows that there also are advantages in terms of environmental impact and cost benefits to using La and perhaps also Ce instead of $\mathrm{Mg}$ in the future alloying concepts. Sn and Ti are the lowest ranking elements and there is only a minimal influence on the strengths of these elements, and their use has primarily others reason than to improve ensile strength

Author Contributions: The contribution from the authors to the current paper were as follows: A.E.W.J. conceived the idea of the paper and acquired the funding from the Knowledge Foundation; A.D. gathered the data used in the analysis and supported the writing with content validity and constructive criticism. G.Y. supervised the work and gave constructive criticism on the work as it progressed; J.Z. and K.W. co-supervised the work of A.D. A.E.W.J., Y.G. and J.Z. acquired the funding from the 1000 Foreign Expert Program together. All authors have read and agreed to the published version of the manuscript.

Funding: The current paper was funded by the Knowledge Foundation under the CompCAST Plus project DNR: 20170066 and by the 1000 Foreign Expert program China and the Chinese Academy of Machinery Science and Technology.

Acknowledgments: The authors would like to acknowledge the kind support of this work from the China Academy of Machinery Science and Technology pro initiation and for providing the opportunity for the collaboration with Jönköping University and the University of Science and Technology, Beijing.

Conflicts of Interest: The authors declare no conflict of interest. The funders had no role in the design of the study; in the collection; analyses; or interpretation of data; in the writing of the manuscript or in the decision to publish the results. The current work is purely a spin-off from another project that was explored out of pure curiosity.

\section{Appendix A}

In the appendix the data used for the fitting to obtain the strengths coefficients are in Table A1.

Table A1. Data used in the fitting of the strength coefficients with compositions in weight \%.

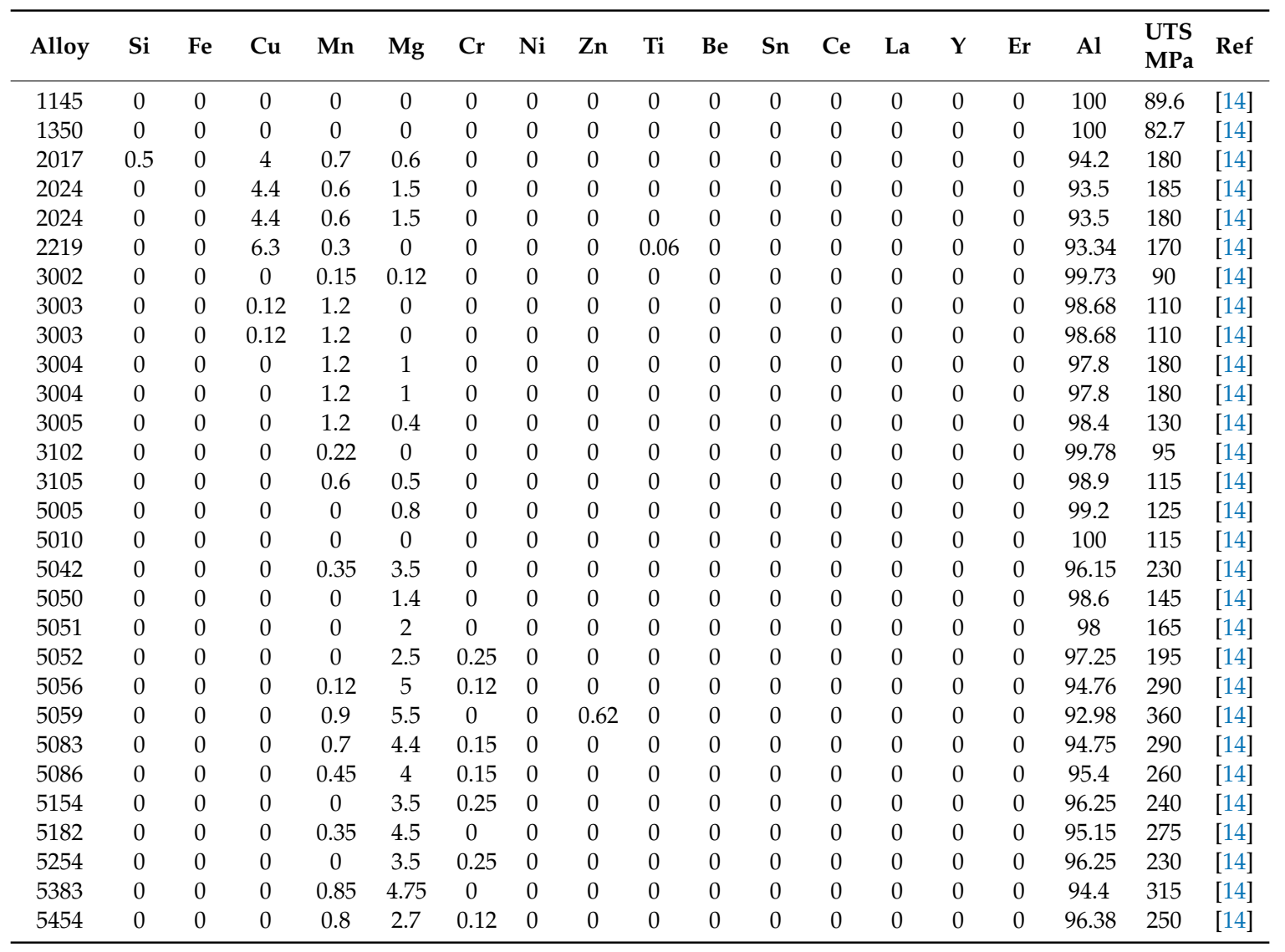


Table A1. Cont.

\begin{tabular}{|c|c|c|c|c|c|c|c|c|c|c|c|c|c|c|c|c|c|c|}
\hline Alloy & $\mathrm{Si}$ & $\mathbf{F e}$ & $\mathrm{Cu}$ & Mn & $\mathbf{M g}$ & $\mathrm{Cr}$ & $\mathrm{Ni}$ & $\mathrm{Zn}$ & $\mathbf{T i}$ & Be & Sn & $\mathrm{Ce}$ & La & $Y$ & Er & Al & $\begin{array}{l}\text { UTS } \\
\text { MPa }\end{array}$ & Ref \\
\hline 5456 & 0 & 0 & 0 & 0.8 & 5.1 & 0.12 & 0 & 0 & 0 & 0 & 0 & 0 & 0 & 0 & 0 & 93.98 & 310 & [14] \\
\hline 5457 & 0 & 0 & 0 & 0.3 & 1 & 0 & 0 & 0 & 0 & 0 & 0 & 0 & 0 & 0 & 0 & 98.7 & 220 & [14] \\
\hline 6061 & 0.6 & 0 & 0.28 & 0 & 1 & 0.2 & 0 & 0 & 0 & 0 & 0 & 0 & 0 & 0 & 0 & 97.92 & 125 & [14] \\
\hline 6061 & 0.6 & 0 & 0.28 & 0 & 1 & 0.2 & 0 & 0 & 0 & 0 & 0 & 0 & 0 & 0 & 0 & 97.92 & 115 & [14] \\
\hline 6063 & 0.4 & 0 & 0 & 0 & 0.7 & 0 & 0 & 0 & 0 & 0 & 0 & 0 & 0 & 0 & 0 & 98.9 & 90 & [14] \\
\hline 6066 & 1.4 & 0 & 1 & 0.8 & 1.1 & 0 & 0 & 0 & 0 & 0 & 0 & 0 & 0 & 0 & 0 & 95.7 & 150 & [14] \\
\hline 7075 & 0 & 0 & 1.6 & 0 & 2.5 & 0.23 & 0 & 5.6 & 0 & 0 & 0 & 0 & 0 & 0 & 0 & 90.07 & 220 & [14] \\
\hline 7178 & 0 & 0 & 2 & 0 & 2.8 & 0.23 & 0 & 6.8 & 0 & 0 & 0 & 0 & 0 & 0 & 0 & 88.17 & 230 & [14] \\
\hline 7178 & 0 & 0 & 2 & 0 & 2.8 & 0.23 & 0 & 6.8 & 0 & 0 & 0 & 0 & 0 & 0 & 0 & 88.17 & 220 & [14] \\
\hline 208.0 & 3 & 0 & 4 & 0 & 0 & 0 & 0 & 0 & 0 & 0 & 0 & 0 & 0 & 0 & 0 & 93 & 245 & [14] \\
\hline 222.0 & 0 & 0 & 10 & 0 & 0.25 & 0 & 0 & 0 & 0 & 0 & 0 & 0 & 0 & 0 & 0 & 89.75 & 185 & [14] \\
\hline 230 & 4 & 1.5 & 10 & 0.6 & 0.25 & 0 & 1 & 1.5 & 0.25 & 0 & 0 & 0 & 0 & 0 & 0 & 80.9 & 205 & [14] \\
\hline 240 & 0 & 0 & 8 & 0.5 & 6 & 0 & 0.5 & 0 & 0 & 0 & 0 & 0 & 0 & 0 & 0 & 85 & 235 & [14] \\
\hline 242 & 0 & 0 & 4 & 0 & 1.5 & 0 & 2 & 0 & 0 & 0 & 0 & 0 & 0 & 0 & 0 & 92.5 & 145 & [14] \\
\hline A242.0 & 0 & 0 & 4.1 & 0 & 1.4 & 0.2 & 2 & 0 & 0.14 & 0 & 0 & 0 & 0 & 0 & 0 & 92.16 & 185 & [14] \\
\hline 295 & 1.1 & 0 & 4.5 & 0 & 0 & 0 & 0 & 0 & 0 & 0 & 0 & 0 & 0 & 0 & 0 & 94.4 & 170 & [14] \\
\hline 308 & 5.5 & 0 & 4.5 & 0 & 0 & 0 & 0 & 0 & 0 & 0 & 0 & 0 & 0 & 0 & 0 & 90 & 195 & [14] \\
\hline 319 & 6 & 0 & 3.5 & 0 & 0 & 0 & 0 & 0 & 0 & 0 & 0 & 0 & 0 & 0 & 0 & 90.5 & 185 & [14] \\
\hline 319 & 6 & 0 & 3.5 & 0 & 0 & 0 & 0 & 0 & 0 & 0 & 0 & 0 & 0 & 0 & 0 & 90.5 & 235 & [14] \\
\hline 328.0 & 8 & 0 & 1.5 & 0.4 & 0.4 & 0 & 0 & 0 & 0 & 0 & 0 & 0 & 0 & 0 & 0 & 89.7 & 170 & [14] \\
\hline 333 & 9 & 0 & 3.5 & 0 & 0.28 & 0 & 0 & 0 & 0 & 0 & 0 & 0 & 0 & 0 & 0 & 87.22 & 235 & [14] \\
\hline 355 & 5 & 0 & 1.25 & 0 & 0.5 & 0 & 0 & 0 & 0 & 0 & 0 & 0 & 0 & 0 & 0 & 93.25 & 160 & [14] \\
\hline C355.0 & 5 & 0 & 1.25 & 0 & 0.5 & 0 & 0 & 0 & 0 & 0 & 0 & 0 & 0 & 0 & 0 & 93.25 & 185 & [14] \\
\hline 356 & 7 & 0 & 0 & 0 & 0.32 & 0 & 0 & 0 & 0 & 0 & 0 & 0 & 0 & 0 & 0 & 92.68 & 165 & [14] \\
\hline 356 & 7 & 0 & 0 & 0 & 0.32 & 0 & 0 & 0 & 0 & 0 & 0 & 0 & 0 & 0 & 0 & 92.68 & 180 & [14] \\
\hline A356.0 & 7 & 0 & 0 & 0 & 0.35 & 0 & 0 & 0 & 0 & 0 & 0 & 0 & 0 & 0 & 0 & 92.65 & 160 & [14] \\
\hline A356.0 & 7 & 0 & 0 & 0 & 0.35 & 0 & 0 & 0 & 0 & 0 & 0 & 0 & 0 & 0 & 0 & 92.65 & 185 & [14] \\
\hline 357 & 7 & 0 & 0 & 0 & 0.52 & 0 & 0 & 0 & 0 & 0 & 0 & 0 & 0 & 0 & 0 & 92.48 & 170 & [14] \\
\hline A357.0 & 7 & 0 & 0 & 0 & 0.55 & 0 & 0 & 0 & 0.12 & 0.055 & 0 & 0 & 0 & 0 & 0 & 92.275 & 195 & [14] \\
\hline 360 & 9.5 & 0 & 0 & 0 & 0.5 & 0 & 0 & 0 & 0 & 0 & 0 & 0 & 0 & 0 & 0 & 90 & 305 & [14] \\
\hline A360.0 & 9.5 & 0 & 0 & 0 & 0.5 & 0 & 0 & 0 & 0 & 0 & 0 & 0 & 0 & 0 & 0 & 90 & 315 & [14] \\
\hline 380 & 8.5 & 0 & 3.5 & 0 & 0 & 0 & 0 & 0 & 0 & 0 & 0 & 0 & 0 & 0 & 0 & 88 & 315 & [14] \\
\hline A380.0 & 8.5 & 0 & 3.5 & 0 & 0 & 0 & 0 & 0 & 0 & 0 & 0 & 0 & 0 & 0 & 0 & 88 & 325 & [14] \\
\hline 383 & 10.5 & 0 & 2.5 & 0 & 0 & 0 & 0 & 0 & 0 & 0 & 0 & 0 & 0 & 0 & 0 & 87 & 310 & [14] \\
\hline 384 & 11.2 & 0 & 3.8 & 0 & 0 & 0 & 0 & 0 & 0 & 0 & 0 & 0 & 0 & 0 & 0 & 85 & 330 & [14] \\
\hline B390.0 & 17 & 0 & 4.5 & 0 & 0.55 & 0 & 0 & 0 & 0 & 0 & 0 & 0 & 0 & 0 & 0 & 77.95 & 315 & [14] \\
\hline 413 & 12 & 0 & 0 & 0 & 0 & 0 & 0 & 0 & 0 & 0 & 0 & 0 & 0 & 0 & 0 & 88 & 295 & [14] \\
\hline A413.0 & 12 & 0 & 0 & 0 & 0 & 0 & 0 & 0 & 0 & 0 & 0 & 0 & 0 & 0 & 0 & 88 & 290 & [14] \\
\hline 443 & 5.2 & 0 & 0 & 0 & 0 & 0 & 0 & 0 & 0 & 0 & 0 & 0 & 0 & 0 & 0 & 94.8 & 130 & [14] \\
\hline B443.0 & 5.2 & 0 & 0 & 0 & 0 & 0 & 0 & 0 & 0 & 0 & 0 & 0 & 0 & 0 & 0 & 94.8 & 160 & [14] \\
\hline C443.0 & 5.2 & 0 & 0 & 0 & 0 & 0 & 0 & 0 & 0 & 0 & 0 & 0 & 0 & 0 & 0 & 94.8 & 115 & [14] \\
\hline A 444.0 & 7 & 0 & 0 & 0 & 0 & 0 & 0 & 0 & 0 & 0 & 0 & 0 & 0 & 0 & 0 & 93 & 145 & [14] \\
\hline A 444.0 & 7 & 0 & 0 & 0 & 0 & 0 & 0 & 0 & 0 & 0 & 0 & 0 & 0 & 0 & 0 & 93 & 165 & [14] \\
\hline 512 & 1.8 & 0 & 0 & 0 & 4 & 0 & 0 & 0 & 0 & 0 & 0 & 0 & 0 & 0 & 0 & 94.2 & 140 & [14] \\
\hline 513 & 0 & 0 & 0 & 0 & 4 & 0 & 0 & 1.8 & 0 & 0 & 0 & 0 & 0 & 0 & 0 & 94.2 & 185 & [14] \\
\hline 514 & 0 & 0 & 0 & 0 & 4 & 0 & 0 & 0 & 0 & 0 & 0 & 0 & 0 & 0 & 0 & 96 & 170 & [14] \\
\hline 518 & 0 & 0 & 0 & 0 & 8 & 0 & 0 & 0 & 0 & 0 & 0 & 0 & 0 & 0 & 0 & 92 & 310 & [14] \\
\hline 535 & 0 & 0 & 0 & 0.18 & 6.8 & 0 & 0 & 0 & 0.18 & 0.005 & 0 & 0 & 0 & 0 & 0 & 92.835 & 240 & [14] \\
\hline 535 & 0 & 0 & 0 & 0.18 & 6.8 & 0 & 0 & 0 & 0.18 & 0.005 & 0 & 0 & 0 & 0 & 0 & 92.835 & 240 & [14] \\
\hline 710 & 0 & 0 & 0.5 & 0 & 0.7 & 0 & 0 & 6.5 & 0 & 0 & 0 & 0 & 0 & 0 & 0 & 92.3 & 220 & [14] \\
\hline 711 & 0 & 1 & 0.5 & 0 & 0.35 & 0 & 0 & 6.5 & 0 & 0 & 0 & 0 & 0 & 0 & 0 & 91.65 & 195 & [14] \\
\hline 712 & 0 & 0 & 0 & 0 & 0.58 & 0.5 & 0 & 6 & 0.2 & 0 & 0 & 0 & 0 & 0 & 0 & 92.72 & 235 & [14] \\
\hline 713 & 0 & 0 & 0.7 & 0 & 0.35 & 0 & 0 & 7.5 & 0 & 0 & 0 & 0 & 0 & 0 & 0 & 91.45 & 220 & [14] \\
\hline Exp. & 0 & 0.16 & 0 & 0 & 3 & 0 & 0 & 0 & 0 & 0 & 0 & 0 & 0 & 0 & 0 & 96.84 & 184 & [13] \\
\hline Exp. & 0 & 0.16 & 0 & 0 & 3 & 0 & 0 & 0 & 0 & 0 & 0 & 0.1 & 0 & 0 & 0 & 96.74 & 202 & [13] \\
\hline Exp. & 0 & 0.16 & 0 & 0 & 3 & 0 & 0 & 0 & 0 & 0 & 0 & 0.2 & 0 & 0 & 0 & 96.64 & 203 & [13] \\
\hline Exp. & 0 & 0.16 & 0 & 0 & 3 & 0 & 0 & 0 & 0 & 0 & 0 & 0.3 & 0 & 0 & 0 & 96.54 & 218 & [13] \\
\hline Exp. & 0 & 0.16 & 0 & 0 & 3 & 0 & 0 & 0 & 0 & 0 & 0 & 0.4 & 0 & 0 & 0 & 96.44 & 210 & [13] \\
\hline Exp. & 0 & 0.16 & 0 & 0 & 3 & 0 & 0 & 0 & 0 & 0 & 0 & 0.5 & 0 & 0 & 0 & 96.34 & 200 & [13] \\
\hline Exp. & 10.86 & 0.57 & 2.95 & 0 & 0.23 & 0 & 0 & 0.68 & 0 & 0 & 0 & 0 & 0 & 0 & 0 & 84.71 & 160 & [15] \\
\hline Exp. & 10.53 & 0.66 & 3.36 & 0 & 0.29 & 0 & 0 & 0.54 & 0 & 0 & 0 & 0 & 0 & 0.12 & 0 & 84.5 & 220 & [15] \\
\hline Exp. & 10.28 & 0.54 & 3.03 & 0 & 0.35 & 0 & 0 & 0.56 & 0 & 0 & 0 & 0 & 0 & 0.23 & 0 & 85.01 & 240 & [15] \\
\hline
\end{tabular}


Table A1. Cont.

\begin{tabular}{|c|c|c|c|c|c|c|c|c|c|c|c|c|c|c|c|c|c|c|}
\hline Alloy & $\mathrm{Si}$ & $\mathrm{Fe}$ & $\mathrm{Cu}$ & Mn & $\mathbf{M g}$ & $\mathrm{Cr}$ & $\mathrm{Ni}$ & $\mathrm{Zn}$ & $\mathrm{Ti}$ & Be & Sn & $\mathrm{Ce}$ & La & Y & Er & Al & $\begin{array}{l}\text { UTS } \\
\text { MPa }\end{array}$ & Ref \\
\hline Exp. & 10.59 & 0.66 & 3.29 & 0 & 0.3 & 0 & 0 & 0.63 & 0 & 0 & 0 & 0 & 0 & 0.34 & 0 & 84.19 & 230 & [15] \\
\hline Exp. & 7.02 & 0.12 & 0.005 & 0.005 & 0.42 & 0 & 0 & 0 & 0.01 & 0 & 0 & 0 & 0 & 0 & 0 & 92.42 & 148 & [16] \\
\hline Exp. & 7.02 & 0.12 & 0.005 & 0.005 & 0.42 & 0 & 0 & 0 & 0.01 & 0 & 0 & 0 & 0 & 0 & 0.2 & 92.22 & 158 & [16] \\
\hline Exp. & 7.02 & 0.12 & 0.005 & 0.005 & 0.42 & 0 & 0 & 0 & 0.01 & 0 & 0 & 0 & 0 & 0 & 0.14 & 92.28 & 169 & [16] \\
\hline Exp. & 7.02 & 0.12 & 0.005 & 0.005 & 0.42 & 0 & 0 & 0 & 0.01 & 0 & 0 & 0 & 0 & 0 & 0.5 & 91.92 & 167 & [16] \\
\hline Exp. & 7.02 & 0.12 & 0.005 & 0.005 & 0.42 & 0 & 0 & 0 & 0.01 & 0 & 0 & 0 & 0 & 0 & 0.6 & 91.82 & 155 & [16] \\
\hline Exp. & 7.02 & 0.12 & 0.005 & 0.005 & 0.42 & 0 & 0 & 0 & 0.01 & 0 & 0 & 0 & 0 & 0 & 0.7 & 91.72 & 154 & [16] \\
\hline Exp. & 7.2 & 0.09 & 0.01 & 0.01 & 0.49 & 0 & 0 & 0.01 & 0 & 0 & 0 & 0 & 0 & 0 & 0 & 92.19 & 230 & [17] \\
\hline Exp. & 7.2 & 0.09 & 0.01 & 0.01 & 0.49 & 0 & 0 & 0.01 & 0 & 0 & 0 & 0 & 0.01 & 0 & 0 & 92.18 & 255 & [17] \\
\hline Exp. & 7.2 & 0.09 & 0.01 & 0.01 & 0.49 & 0 & 0 & 0.01 & 0 & 0 & 0 & 0 & 0.03 & 0 & 0 & 92.16 & 242 & [17] \\
\hline Exp. & 7.2 & 0.09 & 0.01 & 0.01 & 0.49 & 0 & 0 & 0.01 & 0 & 0 & 0 & 0 & 0.05 & 0 & 0 & 92.14 & 249 & [17] \\
\hline Exp. & 7.2 & 0.09 & 0.01 & 0.01 & 0.49 & 0 & 0 & 0.01 & 0 & 0 & 0 & 0 & 0.07 & 0 & 0 & 92.12 & 249 & [17] \\
\hline Exp. & 7.2 & 0.09 & 0.01 & 0.01 & 0.49 & 0 & 0 & 0.01 & 0 & 0 & 0 & 0 & 0.1 & 0 & 0 & 92.09 & 273 & [17] \\
\hline Exp. & 7.2 & 0.09 & 0.01 & 0.01 & 0.49 & 0 & 0 & 0.01 & 0 & 0 & 0 & 0 & 0.3 & 0 & 0 & 91.89 & 272 & [17] \\
\hline Exp. & 7.2 & 0.09 & 0.01 & 0.01 & 0.49 & 0 & 0 & 0.01 & 0 & 0 & 0 & 0 & 0.5 & 0 & 0 & 91.69 & 273 & [17] \\
\hline Exp. & 7.2 & 0.09 & 0.01 & 0.01 & 0.49 & 0 & 0 & 0.01 & 0 & 0 & 0 & 0 & 1 & 0 & 0 & 91.19 & 230 & [17] \\
\hline Exp. & 11 & 0.4 & 1.5 & 0 & 0.3 & 0 & 0 & 0 & 0 & 0 & 0 & 0 & 0 & 0 & 0 & 86.8 & 240 & [18] \\
\hline Exp. & 11 & 0.4 & 1.5 & 0 & 0.3 & 0 & 0 & 0 & 0 & 0 & 0 & 0 & 0.5 & 0 & 0 & 86.3 & 245 & [18] \\
\hline Exp. & 11 & 0.4 & 1.5 & 0 & 0.3 & 0 & 0 & 0 & 0 & 0 & 0 & 0 & 0.1 & 0 & 0 & 86.7 & 260 & [18] \\
\hline Exp. & 11 & 0.4 & 1.5 & 0 & 0.3 & 0 & 0 & 0 & 0 & 0 & 0 & 0 & 0.2 & 0 & 0 & 86.6 & 250 & [18] \\
\hline Exp. & 0.65 & 0.13 & 0.27 & 0 & 0.95 & 0.15 & 0 & 0 & 0 & 0 & 2 & 0 & 0 & 0 & 0 & 95.85 & 157 & [18] \\
\hline
\end{tabular}

\section{References}

1. Kenworthy, J.R. Transport Energy Use and Greenhouse Gases in Urban Passenger Transport Systems: A Study of 84 Global Cities. In Proceedings of the International Sustainability Conference, Fremantle, Western Australia, 17-19 September 2003; pp. 1-28.

2. Hooftman, N.; Messagie, M.; Van Mierlo, J.; Coosemans, T. A review of the European passenger car regulations-Real driving emissions vs local air quality. Renew. Sustain. Energy Rev. 2018, 86, 1-21. [CrossRef]

3. Serrenho, A.C.; Norman, J.B.; Allwood, J.M. The impact of reducing car weight on global emissions: The future fleet in Great Britain. Philos. Trans. A. Math. Phys. Eng. Sci. 2017, 375, 20160364. [CrossRef] [PubMed]

4. Jarfors, A.E.W.; Kainer, K.-U.; Tan, M.-J.; Yong, J. Recent developments in the manufactruing of components from Aluminum-, Magnesium- and Titanium-based alloys. Cosmos 2009, 5, 23-58. [CrossRef]

5. Jarfors, A.; Bejhem, M.; Carlsson, T.; Eliasson, A.; Keife, H.; Nicolescu, C.-M. Tillverkningsteknologi; 4 (2010); Studentlitteratur: Lund, Sweden, 1999; 637p.

6. Dieter, G.E. Mechanical Metallurgy; McGraw-Hill Book Company: New York, NY, USA, 1961.

7. Ceschini, L.; Dahle, A.; Gupta, M.; Wollmar, A.E.; Jayalakshmi, J.S.; Morri, A.; Rotundo, F.; Toschi, S.; Singh, R.A. Engineering Materials Aluminum and Magnesium Metal Matrix Nanocomposites; Springer Nature: Singapore, 2017; p. 171.

8. CES EduPack 2019, Version 19.2.0, Software; Granta Design Limited: Cambridge, UK, 2019.

9. Charney, J.G.; Arakawa, A.; Baker, D.J.; Bolin, B.; Dickinson, R.E.; Goody, R.M.; Leith, C.E.; Stommel, H.M.; Wunsch, C.I. Carbon Dioxide and Climate: A Scientific Assessment; National Academy of Sciences: Washington, DC, USA, 1979.

10. Casarotto, F.; Franke, A.J.; Franke, R. High-Pressure Die-Cast (HPDC) Aluminum Alloys for Automotive Applications; Woodhead Publishing: Sawston, Cambridge, UK, 2012.

11. Nee, A.Y.C. Handbook of Manufacturing Engineering and Technology; Springer Nature: London, UK, 2015.

12. Nonferrous Metals. Available online: https://www.ccmn.cn/priceinfo/ (accessed on 16 September 2019).

13. Zhang, X.; Wang, Z.; Zhou, Z.; Xu, J. Influence of rare earth (Ce and La) addition on the performance of Al-3.0 wt\%Mg alloy. J. Wuhan Univ. Technol. - Mater. Sci. Ed. 2017, 32, 611-618. [CrossRef]

14. Anderson, K.; Weiritz, J.; Kaufman, J.G. Properties and Selection of Aluminum Alloys; ASM International: Novelty, OH, USA, 2019.

15. Liu, J.; Wu, Q.; Yan, H.; Zhong, S.; Huang, Z. Effect of trace yttrium addition and heat treatment on the microstructure and mechanical properties of as-cast ADC12 aluminum alloy. Appl. Sci. 2018, 9, 53. [CrossRef] 
16. Li, X.-Y.; Lu, Y.-L.; Wang, J.; Zhou, D.; Yang, L. Effect of Rare Earth Erbium on Microstructure and Mechanical Properties of A356 Aluminum Alloy. J. Mater. Eng. 2018, 46, 67-73.

17. Pourbahari, B.; Emamy, M. Effects of La intermetallics on the structure and tensile properties of thin section gravity die-cast A357 Al alloy. Mater. Des. 2016, 94, 111-120. [CrossRef]

18. Lu, T.; Pan, Y.; Wu, J.-L.; Tao, S.-W.; Chen, Y. Effects of La addition on the microstructure and tensile properties of Al-Si-Cu-Mg casting alloys. Int. J. Miner. Metall. Mater. 2015, 22, 405-410. [CrossRef]

(C) 2020 by the authors. Licensee MDPI, Basel, Switzerland. This article is an open access article distributed under the terms and conditions of the Creative Commons Attribution (CC BY) license (http://creativecommons.org/licenses/by/4.0/). 